Ссылка: Бурденко Е.В., Герасимова Н.В. Формирование инвестиционного спроса в современной России// Наука и образование. Новые технологии: Межвузовский сборник научных трудов, - М.: ИИЦ МГУДТ. 2004. с. 143-155.

$\underline{\text { http://elibrary.ru/item.asp?id=24914524 }}$

\title{
ФОРМИРОВАНИЕ ИНВЕСТИЦИООНОГО СПРОСА В СОВРЕМЕННОЙ РОССИИ
}

Бурденко Елена Викторовна - почетный работник высшего профессионального образования, кандидат экономических наук, доцент кафедры политической экономии Российского экономического университета им. Г.В. Плеханова, ResearcherID: E-3369-2014

orcid.org/0000-0001-5073-5062

burdenko-ev@yandex.ru

Герасимова Н.B. - студентка Российской экономической академии им. Г.В. Плеханова.

\section{Аннотация}

В статье рассмотрены проблемы формирования инвестиционного спроса в трансформируемой экономике России.

Ключевые слова: инвестиции, экономика России.

\section{THE FORMATION OF INVESTMENT DEMAND IN MODERN RUSSIA}

Burdenko, Elena V. - honorary worker of higher professional education, $\mathrm{PhD}$, Assistant Professor of the Department for Political Economy of the Russian University of Economics,

ResearcherID: E-3369-2014

orcid.org/0000-0001-5073-5062

burdenko-ev@yandex.ru

Gerasimova N.V. - student of the Plekhanov Russian University of Economics

Abstract

The article considers problems of formation of investment demand transformed the economy of Russia.

Keywords: investment, the economy of Russia. 


\section{УДК: 330.332}

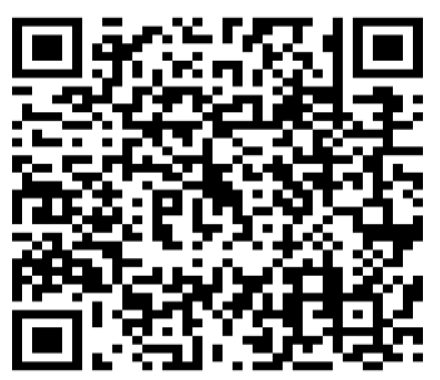

ФОРМИРОВАНИЕ ИНВЕСТИЦИООНОГО СПРОСА В СОВРЕМЕННОЙ РОССИИ

Бурденко Е.В., Герасимова Н.В., Российская экономическая академия им.Г.В.Плеханова

Любое государство, заинтересованное в привлечении свободных финансовых средств потенциальных инвесторов в национальную экономику, в соответствии с государственной инвестиционной политикой уделяет огромное внимание грамотному и эффективному формированию инвестиционного спроса.

В последние годы в народном хозяйстве России сложились уникальные возможности для выхода из кризиса на основе роста инвестиций и производства. В России сформировался значительный потенциал ресурсов для инвестирования. Проблема, однако, в том, что данные ресурсы в значительной своей части не используются на цели накопления и инвестирования в основной капитал, а экономика в последнее время теряет темпы инвестиционного оживления.

Причины такой ситуации кроются в особенностях сформировавшейся воспроизводственной модели российской экономики, характеризующейся, в частности:

I) усилением ее зависимости от конъюнктуры мировых рынков сырья и поддержанием роста посредством высокоинтенсивной эксплуатации производственного аппарата экспортоориентированного сектора, приближающейся к предельно возможному уровню загрузки мощностей;

2) накоплением в стране масштабного потенциала сбережений, в значительной своей части не используемого на инвестиции в реальные активы; 
3) высокой концентрацией этого потенциала в отраслях экспортоориентированного сектора промышленности на фоне обострения дефицита инвестиционных капиталов в обрабатывающем комплексе, увеличением разрыва в прибыльности производств в этих секторах;

4) ростом масштабов финансирования зарубежных экономик за счет ресурсов экспортного сектора (вывоз капитала, накопление валютных резервов в государственном и частном секторах экономики);

5) неразвитостью каналов межотраслевого перетока капиталов из капиталодостаточных в капиталодефицитные отрасли промышленности;

6) невозможностью поддерживать устойчивую и высокую динамику экономического роста только за счет экспортоориентированного сектора экономики

Сегодня привлечение инвестиций в реальный сектор экономики - вопрос ее выживания. Будут инвестиции - будет развитие реального сектора, a, следовательно, будет и экономический подъем. Не удастся привлечь - неминуемо умирание производств, деградация экономики, обнищание государства, социальные взрывы и прочие сопутствующие явления. Любое, даже самое незначительное, улучшение инвестиционного климата - это дополнительные средства, позволяющие сделать шаг к выходу из кризиса. Осуществить превращение инвестиций в динамически устойчивый мощный поток возможно, лишь управляя процессом улучшения инвестиционного климата. Именно поэтому проблема управления инвестиционной привлекательностью является ключевой на сегодняшний день. Для ее решения необходимо найти или создать массовую технологию управления инвестиционной привлекательностью.

Следует отметить недостаточную эффективность инвестиционной политики России последнего десятилетия. Сам «центр», создавая в начале десятилетия на обломках рухнувшей модели монопольного централизованного государственного инвестирования рыночную модель инвестиционного процесса, провозгласил принцип его радикальной децентрализации, в том числе в региональном плане. 
Эта политика не принесла ожидаемых результатов, при более чем скромном объеме инвестиций, пришедших в Россию в 90-е годы.

Уже в Федеральной адресной инвестиционной программе на 2000 год, обращает на себя внимание постановка задачи повышения роли федерального уровня в политике привлечения иностранного капитала. Это обусловлено стремлением федеральных властей вернуть бразды правления инвестиционным процессом (включающим и привлечение отечественных капиталовложений) в свои руки и необходимостью на базе осмысления накопленного в последние годы регионального опыта сформировать более действенные, чем ранее, механизмы государственной инвестиционной политики.

Привлечение иностранных инвестиций в любую страну, а также эффективность капиталовложений определяются преимуществами

инвестиционного климата в данной стране. От него зависит главным образом формирование инвестиционного спроса, как на макро- так и на микроэкономическом уровне.

Оценивая российскую действительность с позиций необходимости создания в стране благоприятного инвестиционного климата, следует признать, что комплекс подлежащих решению проблем сближает Россию скорее с развивающимися, чем с промышленно развитыми странами. Специфическая особенность состоит, например, в том, что в стране пока не созданы условия для существования единообразного инвестиционного климата на всем ее экономическом пространстве.

На микроуровне это проявляется в том, что только малая часть потенциальных объектов для инвестирования готова к эффективному использованию средств в силу неприемлемо низкого качества управления.

На региональном уровне существует отчетливо проявляющаяся дифференциация субъектов Федерации по инвестиционному климату. Львиная доля инвестиций (отечественных и иностранных) сосредоточена в регионах с высоким потенциалом и незначительным риском. Это особенно характерно для иностранных инвесторов. Отечественные же инвесторы проявляют большую, чем 
иностранцы, готовность вкладывать свои капиталы в регионы с высоким риском при наличии у них высокого инвестиционного потенциала.

Таким образом, при характеристике инвестиционного климата в России, вероятно, еще достаточно долго придется считаться с существованием значительных различий в условиях инвестирования в зависимости от обстановки в регионах и степени готовности отдельных предприятий и даже отраслей к эффективному использованию инвестиционных ресурсов.

В России, к сожалению, до сих пор отсутствует своя система оценки инвестиционного климата страны в целом и ее отдельных регионов. Иностранные инвесторы ориентируются на результаты многочисленных консалтинговых фирм, систематически анализирующих инвестиционный климат во многих странах мира, в том числе и в России. Однако оценки инвестиционного климата в России, даваемые зарубежными экспертами на их регулярных заседаниях, проводимых вне РФ и без участия российских экспертов, представляются малодостоверными, а возможно, и ангажированными.

В Федеральной адресной инвестиционной программе на 2002 год, также обращает на себя внимание постановка задачи повышения роли федерального уровня в политике привлечения иностранного капитала. Однако в 90-е годы некоторые российские регионы довольно успешно освоили инструменты привлечения инвесторов на свои территории, минуя федеральный «центр».

Формирование инвестиционной политики регионов происходило в весьма различных стартовых условиях при дифференциации уровней развития и обеспеченности факторами производства, разной производственной специализации, и т.п. Неодинаковыми были и пути преодоления инвестиционных трудностей. В целом анализ пореформенной хозяйственной динамики в крупных экономических районах России выявляет ухудшение инвестиционной ситуации в направлении «северо-запад - юго-восток страны». Эта проблема сохранится и будет усугубляться при отсутствии действенной государственной региональной инвестиционной политики, направленной хотя бы на ослабление 
территориальных диспропорций. Сами высокопоставленные работники Минэкономики России признают, что если целенаправленно не распределять инвестиции по всему российскому пространству, неизбежна еще более значительная дифференциация регионов, чреватая развалом страны.

Некоторые руководители регионов сегодня продолжают делать ставку на «выбивание» средств федерального бюджета, другие до сих пор надеются на свои бюджетные возможности. Между тем доля федерального бюджета в общем объеме инвестиций за счет всех источников финансирования в российскую экономику на протяжении последних лет сокращалась: в 2000 г. она составила 5,1\%, а на 2003 г. не превысила 3,6\%. Инвестиционные расходы субъектов Федерации и местных бюджетов держатся на уровне чуть выше 10\% всех инвестиций. В целом объем государственных инвестиций, которые должны были быть профинансированы в 2003 г. из федерального бюджета, составил 11706 млн. руб., из коих 610 млн. пошли на формирование резервного фонда Бюджета развития РФ под госгарантии. Таким образом, и в бюджете-2003 отсутствует ориентация на государственную инвестиционную поддержку производства и создание реальных предпосылок экономического роста. ${ }^{1}$

Активизация собственной инвестиционной политики в регионах среди прочего обусловливается ростом в них социальной напряженности, связанным, в частности, со «сбросом» социальных расходов с федерального на региональные бюджеты, не имеющие соответствующей доходной базы. О возрастающих социальных рисках в обществе, подавляющих по ряду направлений инвестиционный потенциал, свидетельствует то, что в течение 90-х годов ухудшается весь комплекс показателей, отражающих доходы населения и уровень жизни. Средние по России данные еще более контрастно проявляются на региональном уровне, характеризуя усиление социально-экономических различий между субъектами Федерации. После августа-98 число россиян с денежными доходами ниже прожиточного минимума устойчиво превышает треть общей численности населения, а коэффициент дифференциации доходов

\footnotetext{
${ }^{1}$ По данным Российского статистического ежегодника, 2003г., стр. 597
} 
крайних децильных групп, показывающий колоссальное расслоение общества, увеличился в 1999 г. до 14,7 раз. По итогам 1999 г. реальные доходы населения оказались ниже уровня 1998 г. (который в свою очередь был ниже уровня 1997 г.). В принятом в самом конце 1999 г. федеральном бюджете страны на 2000 г. вопросы оплаты труда бюджетников (остающейся значительно ниже прожиточного минимума) решены откровенно неудовлетворительно.

По данным Минэкономики России, к середине 1999 г. 69 регионов в рамках своей компетенции приняли юридические акты, направленные на поощрение инвестиций и касающиеся создания зон наибольшего благоприятствования, предоставления налоговых льгот, оказания кредитной поддержки строительства, выделения земли, развития лизинговой деятельности, и т.п. В общей сложности в субъектах РФ разного уровня (республиках, краях, областях, автономных образованиях) принято 80 соответствующих правовых актов, в том числе 50 законов. Только в 1999 г. появились региональные законодательные и иные акты по вопросам господдержки и стимулирования инвестиционной деятельности в Смоленской, Тамбовской и Новосибирской областях, в Краснодарском крае. Разрабатывается законодательство, направленное на активизацию притока иностранных инвестиций, в Карачаево-Черкесской Республике и Республике Хакасия, Орловской, Рязанской, Тверской, Читинской, Камчатской и Сахалинской областях.

Лидерами в разработке собственной инвестиционной политики, еще в 19931994 гг. выступали республика Коми, Саха-Якутия и Татарстан. Их усилия были направлены на привлечение иностранных инвесторов, что выразилось в принятии законов, определяющих благоприятные условия деятельности в этих регионах зарубежного капитала. Республика Татарстан, проводя политику мягкого вхождения на рынок, приняла ряд нормативных документов - законов, президентских указов и правительственных постановлений, - направленных на формирование благоприятного климата для инвесторов и на их поддержку (законы «Об иностранных инвестициях в Республике Татарстан», «О статусе одобренного инвестиционного проекта с участием иностранного инвестора» и 
«Об инвестиционной деятельности в Республике Татарстан», президентский указ «О государственной поддержке предпринимательства в Республике Татарстан» и др.). В 1998 г. в экономику республики было вложено иностранных инвестиций на сумму около 700 млн. долл., что в семь раз превышает показатель 1996 г. Сегодня Татарстан, войдя в десятку российских регионов, где суммарно сосредоточены $80 \%$ вложений иностранного капитала, обрел репутацию стабильного региона с относительно низким уровнем риска для зарубежных инвесторов (окрестивших РТ «островом прагматизма» и «естественным магнитом»). В 1999 г. между республиканским правительством, администрацией г. Казани и городскими промышленными предприятиями был заключен ряд соглашений о социально-экономическом сотрудничестве: правительство и мэрия города снизили налоги на прибыль, добавлению стоимость и на имущество, а также обеспечили предприятия республиканским и муниципальным госзаказом; предприятия в свою очередь гарантируют властям текущие платежи, рост производства, повышение заработной платы и сохранение рабочих мест; в соглашении записано, что остающиеся в распоряжении производителей средства должны направляться только на инвестирование производства.

С некоторым отставанием к процессу задействования собственного инвестиционного права подключились областные образования России, причем принимаемые ими акты изначально нацеливались на одинаковые параметры стимулирования всех потенциальных инвесторов (ибо становилось все более очевидным, что широкомасштабных иностранных инвестиций в экономику, из которой в силу неблагоприятных условий уходит отечественный инвестор, не будет). Так, в конце 1996 г. появился Закон «О гарантиях частных инвестиций в Нижегородской области», распространяющийся на отечественных и иностранных инвесторов. В этом акте прописаны столь необходимые гарантии сохранности капитала, источники которых - средства областного бюджета, активы областных внебюджетных фондов, природно-сырьевые ресурсы и недвижимость, находящиеся в собственности региона. 
Федеральные адресные инвестиционные программы России последних лет дают обширный информационный материал о формах содействия инвестиционным процессам в ряде регионов. В конце 1997 г. в Новгороде состоялось крупное общероссийское совещание по проблемам региональной инвестиционной политики. Многие субъекты РФ развернули рассчитанную на внешних инвесторов активную информационную компанию. Периодические издания («Эксперт», «Инвестиционный потенциал России», «Экономика и жизнь» и многие другие) регулярно публикуют материалы об инвестиционной привлекательности тех или иных регионов и их соответствующих рейтингах, каталоги разработанных инвестиционных проектов. И все же процесс инвестирования развивается недостаточно активно. К существующим здесь трудностям, как заявляют сами иностранные предприниматели, относятся, прежде всего, противоречия между федеральным и региональным законодательствами, в первую очередь в сфере налогообложения; бюрократизм и коррупция при вышеотмеченных зацентрализованных лицензировании и регистрации; и т.п.

Основными элементами сформировавшейся в течение десятилетия в субъектах Российской Федерации инвестиционной политики являются:

1) принятие собственного законодательства, регулирующего инвестиционный процесс;

2) предоставление (в пределах своих полномочий) инвесторам различных льгот и стимулов финансового и нефинансового характера;

3) создание организационных структур по содействию инвестициям;

4) разработка и экспертиза инвестиционных проектов за счет государственных источников финансирования;

5) оказание содействия инвесторам в получении таможенных льгот;

6) предоставление гарантий и поручительств банкам под выделенные ими средства для реализации отобранных на конкурсной основе инвестиционных проектов; 
7) аккумулирование средств населения путем выпуска муниципальных займов. Можно отметить, что формы и методы стимулирования инвесторов российскими регионами соответствуют мировой практике.

В большинстве российских регионов, испытывающих нехватку финансовых средств для прямой поддержки конкретных проектов, используются преимущественно косвенные ее формы. Это, во-первых, освобождение на определенных условиях от уплаты в региональный бюджет налога на прибыль и налога на имущество (снижение их ставок). Во-вторых, - отсрочки по налогам и арендным платежам. В-третьих, - предоставление зданий и земель, право распоряжения, которыми принадлежит региональным или муниципальным администрациям. В-четвертых, - выдача гарантий региональных и местных органов власти. Задействование перечисленных форм поддержки инвесторов на начальных этапах (до начала получения отдачи от проектов), как показывает практика, зачастую приводит к росту социальной напряженности. Дело в том, что предоставляемые инвесторам льготы по уплате налогов (в пределах компетенции субъектов Федерации) приводят к недобору средств в доходную часть соответствующих бюджетов, из которой выплачивается заработная плата работникам бюджетной сферы и финансируется социальная инфраструктура региона. В этих условиях региональным администрациям приходится делать выбор: сохранение льгот инвесторам или регулярная выплата зарплаты бюджетникам. Что касается перехода от налоговых льгот к прямой поддержке инвестиционных проектов, то на это решаются только наиболее сильные в финансовом отношении субъекты Федерации.

Примером относительно высокой результативности региональных усилий по стимулированию инвестиций может служить Новгородская область, где нет особо привлекательных запасов природных ресурсов. В 90-е годы здесь создана вполне современная система привлечения инвестиций и сопровождения инвесторов. Комплекс налоговых льгот и закрепляющих их правовых актов формировался поэтапно, начиная с 1994 г., а в 1998 г. появился Закон об инвестиционной деятельности в Новгородской области, в котором сведены 
вместе все ранее введенные «правила игры». В документе четко обозначены, в частности, наиболее привлекательные для иностранных инвесторов, стремящихся минимизировать риски, гарантии со стороны органов областного руководства. Это: 1) гарантийный фонд, предусмотренный статьей 2 Закона о бюджете Новгородской области; 2) полное бесплатное информационное обеспечение потенциальных инвесторов; 3) сопровождение перспективных проектов областным экономическим комитетом и оказание помощи в разрешении проблем, касающихся федеральных органов власти

Итак, с одной стороны, многие регионы России за короткий срок сформировали более цельную и последовательную, чем на федеральном уровне, инвестиционную политику. С другой стороны, качественного перелома не происходит: масштабного притока инвестиций нет притом, что развивается довольно напряженная конкурентная борьба между регионами за инвестора путем предоставления все новых льгот, гарантий и т.п. Для изменения ситуации необходимо (как признают представители наиболее «продвинутых» в отношениях с иностранными инвесторами регионов) снизить суверенный российский риск, т.е. сломать представление о России как о ненадежном партнере.

Эффективность инвестиционной политики (формирования инвестиционного спроса) России последних 13-ти лет не обеспечивает достаточного притока инвестиций в экономику. А он необходим для обеспечения нормального развития экономики. Для формирования эффективной инвестиционной политики необходимо учесть опыт регионов, ведь там за последние годы было разработано немало инвестиционных программ, давших свои плоды.

Основными элементами сформировавшейся в течение десятилетия в субъектах Российской Федерации инвестиционной политики являются:

1) принятие собственного законодательства, регулирующего инвестиционный процесс;

\footnotetext{
${ }^{2}$ Инвестиционная политика: диалектика регионального и федерального уровней //М:, Российский экономический журнал, №5, 2002
} 
2) предоставление (в пределах своих полномочий) инвесторам различных льгот и стимулов финансового и нефинансового характера;

3) создание организационных структур по содействию инвестициям;

4) разработка и экспертиза инвестиционных проектов за счет государственных источников финансирования;

5) оказание содействия инвесторам в получении таможенных льгот;

6) предоставление гарантий и поручительств банкам под выделенные ими средства для реализации отобранных на конкурсной основе инвестиционных проектов.

В ближайшее время необходима реализация инвестиционно ориентированной государственной политики, основными элементами которой являются:

- государственное регулирование ставки процента на уровне, сопоставимом со средним показателем рентабельности в отраслях реального сектора экономики;

- государственная политика страховых гарантий для инвестиционных потоков;

- переориентация фискально-ориентированной налогово-бюджетной политики на инвестиционно - ориентированную политику;

- государственная поддержка национальных и региональных проектов;

- защита отечественных инвесторов, как в стране, так и за рубежом;

- улучшение информационного и кадрового обеспечения инвестиционного процесса;

• выделение финансовой помощи государством на оздоровление предприятий (санация);

- содействие иностранным инвесторам.

Для стимулирования инвестиций нужны не только стабильность и прозрачность «правил игры», но и тесное взаимодействие крупнокорпоративного бизнеса и государства в определении тенденций экономического развития (то, что в литературе квалифицируется как составляющая «индикативного планирования»), а также четкое управление инвестиционными процессами в 
государственном секторе. От того, насколько быстро удастся решить эту задачу, во многом будет зависеть успех всей правительственной социальноэкономической политики в среднесрочной перспективе.

Литература:

1. Инвестиционная политика: диалектика регионального и федерального уровней // М: Российский экономический журнал, №5, 2002

2. Российский статистический ежегодник // M: 2003г, с. 597 